\title{
GRAMÁTICA \\ DE LIBRAS: \\ QUESTÕES \\ METODOLÓGICAS
}

GRAMÁTICA DE LIBRAS: CUESTIONES METODOLÓGICAS

LIBRAS GRAMMAR: METHODOLOGICAL ISSUES

Ronice Müller de Quadros*

Universidade Federal de Santa Catarina

Jair Barbosa da Silva**

Universidade Federal de Alagoas

Miriam Royer***

Universidade Federal de Santa Catarina

RESUMO: Por que fazer descrições gramaticais de línguas de sinais? Por que descrever a gramática da língua brasileira de sinais Libras? Os estudos linguísticos da Libras iniciaram na década de 90 (FERREIRA-BRITO, 1995) e começaram a ter mais evidência depois da Lei de Libras - 10.436/2002 - e da criação dos cursos de Letras Libras, em 2005. No entanto, os estudos desta língua iniciam-se com descrições linguísticas a partir de dados individuais, "ideais" (CHOMSKY, 1986) por não haver um corpus linguísitico disponível, a exemplo do Corpus de Libras. Os trabalhos são pontuais e abordam questões específicas da língua. Metodologicamente, essas pesquisas esbarram no fato de se depararem com sinalizantes que apresentam grande variação entre si quanto ao processo de aquisição da língua. Diante da diversidade aquisicional da Libras no Brasil, torna-se fundamental constituir estudos gramaticais dessa língua de modo consistente e robusto, baseado em corpora representativos da diversidade linguística do país. A descrição gramatical da Libras faz-se necessária para oferecer uma compreensão da língua para professores de língua de sinais de crianças surdas, para formação de professores de Libras e tradutores e intérpretes, assim como para profissionais da área da linguagem que necessitam de conhecimento da língua para indicarem planos de intervenção linguística para pessoas surdas. $\mathrm{O}$ objetivo deste artigo é apresentar aspectos metodológicos a serem considerados na constituição de gramáticas de línguas de sinais, com foco na elaboração de gramáticas da Libras, com dados do Corpus de Libras, usando a ferramenta SignGram Blueprint, desenvolvida para descrever línguas de sinais.

PALAVRAS-CHAVE: Descrição gramatical. Gramática da Libras. Metodologia para construcão de gramática.

\footnotetext{
* Professora e pesquisadora da Universidade Federal de Santa Catarina, no Departamento de Libras e pesquisadora do CNPQ. E-mail:ronice.quadros@ufsc.br.

** Professor e pesquisador da Universidade Federal de Alagoas. E-mail: jair.silva@fale.ufal.br

*** Doutoranda do Programa de Pós-Graduação em Linguística, na Universidade Federal de Santa Catarina. E-mail: miriam15royer@gmail.com.
} 
RESUMEN: ¿Por qué hacer descripciones gramaticales de lengua de señas? ¿Por qué describir la gramática de la lengua de señas brasileña - Libras? Los estudios lingüísticos de Libras iniciaron en los años 90 (FERREIRA-BRITO, 1995) y empezaron a tener más visibilidad a partir de la Ley de Libras - 10.436/2002 - y de la creación de los cursos de Letras Libras en 2005. Sin embargo, los estudios de esta lengua se inician con descripciones lingüísticas basadas en datos individuales, "ideales" (CHOMSKY, 1986) al no existir un corpus lingüístico disponible, como el Corpus de Libras. Los trabajos son puntuales y abordan cuestiones específicas de la lengua. Metodológicamente, estas investigaciones se topan con el hecho de que encuentran usuarios que muestran una gran variación entre sí en cuanto al proceso de adquisición de la lengua. Dada la diversidad de adquisición de Libras en Brasil, es fundamental establecer estudios gramaticales de esta lengua de manera consistente y robusta, basados en corpus representativos de la diversidad lingüística del país. La descripción gramatical de Libras es necesaria para ofrecer una comprensión de la lengua a los profesores que enseñan lengua de señas a niños sordos, para la formación de profesores de Libras, traductores e intérpretes, así como para los profesionales del lenguaje que necesitan conocimientos de la lengua al orientar planes de intervención lingüística para personas sordas. El objetivo de este artículo es presentar aspectos metodológicos que deben ser considerados en la constitución de gramáticas de lenguas de señas, enfocándose en la elaboración de las gramáticas de Libras, con datos del Corpus de Libras, utilizando la herramienta SignGram Blueprint, desarrollada para describir las lenguas de señas.

PALABRAS CLAVE: Descripción gramatical. Gramática de Libras. Metodología para la elaboración de gramática.

ABSTRACT: Why should we have to do grammatical descriptions of sign languages? Why do we need to describe the grammar of the Brazilian sign language - Libras? Libras linguistic studies started in the 90's (FERREIRA-BRITO, 1995), but it began to have more evidence after the Libras Law 10,436/2002, and the creation of Letras Libras courses, in 2005. However, studies of this language with linguistic descriptions were based on the signer's intuition (CHOMSKY, 1986), because there was no linguistic corpus available, like we have nowadays, the Corpus of Libras. The works were punctual and addressed specific language issues. Methodologically, these researches revealed that signers show great variation among themselves in terms of their language acquisition process. Considering this diversity in Brazil, it turned out to be essential to establish grammatical studies of this language in a consistent and robust manner, based on representative corpora of the Libras linguistic diversity. The actual grammatical description of Libras is necessary to provide an understanding of the language for sign language teachers of deaf children, for the training of Libras teachers and translators and interpreters, as well as for language professionals who need knowledge of the language to indicate language intervention plans for deaf people. The goal of this article is to present methodological aspects to be considered in the constitution of sign language grammars, focusing on the development of Libras grammar, with data from the Corpus of Libras, using the SignGram Blueprint tool developed to describe sign languages.

KEYWORDS: Grammatical description. Grammar of Libras. Grammar development methodology.

\section{INTRODUÇÃO}

O primeiro curso de Letras Libras no Brasil foi criado em 2006, pela Universidade Federal de Santa Catarina. Considerando o inevitável impacto social e político que um curso superior impõe a seus usuários e à sociedade como um todo, o fato de a Libras passar a compor a agenda de estudos em nível superior na universidade brasileira trouxe à tona uma série de importantes questões:

1. Qual o estado da arte da descrição da Libras no Brasil?

2. Como era o uso, a gramática e os aspectos culturais da Libras em períodos anteriores (há 10, 20, 30, 40, 50... anos atrás?)

3. Como fazer pesquisa para uma língua em que não há registros escritos sobre ela e, ademais, sendo uma língua de modalidade visuo-espacial?

4. Como ensinar essa língua? Qual o seu papel nas escolas? Qual material didático usar? Há material voltado para cada nível de ensino (Educação Infantil, Ensinos Fundamental, Médio e Superior? Quem deve ensinar esta língua? Qual a formação requerida? 5. Qual(is) metodologia(s) usar para a pesquisa e para o ensino da Libras?

Muitas são as perguntas, poucas as respostas. A Libras, em termos de espaço acadêmico, pode ser considerada embrionária no que concerne à pesquisa e ao consequente desenvolvimento de recursos voltados para a própria pesquisa e para o ensino. A partir de 
2011, por meio do Plano Nacional de Direitos da Pessoa com Deficiência, referido como Programa Viver sem Limites, o curso de Letras-Libras, inicialmente proposto e implantado pela/na UFSC, é expandido para cerca de 27 universidades brasileiras. Paradoxalmente, se por um lado pode-se reconhecer uma excelente conquista político-educacional, sobretudo, um grande ganho para as pessoas surdas, por outro, há de se reconhecer a enorme carência de recursos materiais e humanos com que estes cursos foram implantados no Brasil.

Os cursos criados, desde então, demandam materiais disponíveis sobre a Libras, em especial de livros textos, teóricos e aplicados, bem como, de gramáticas que descrevam e expliquem os fenômenos linguísticos desta língua. Além disso, o fato de estar instituída uma educação bilíngue para surdos faz com que os professores busquem por materiais sobre a Libras para subsidiar um currículo de ensino desta língua como L1 (para os alunos surdos) e como L2 (para os alunos ouvintes) nas universidades e nas escolas bilíngues (Libras e Língua Portuguesa).

A partir disso, torna-se relevante o desenvolvimento de gramáticas da Libras abrangendo alguns níveis linguísticos específicos. Esta gramática torna-se possível neste momento, considerando os estudos que já foram realizados ao longo dos anos no Brasil (tais como, QUADROS, 1999; QUADROS; KARNOPP, 2004; ARROTÉIA, 2005; XAVIER, 2006; 2014; LEITE, 2008; NASCIMENTO, 2009 ; SILVA, 2013; FERREIRA, 2013; MIRANDA, 2014; LOURENÇO, 2014; ANDRADE, 2015; QUADROS; PIZZIO, 2015; SABANAI, 2016; XAVIER; NEVES, 2016), assim como, diante do Inventário Nacional de Libras, que conta com produções em Libras devidamente transcritas e anotadas (por exemplo, CNPQ Processos 234255/2013-7; 303725/2013-3; 471355/2013-5; 304102/20105; 471478/2010-5; e Ministério da Cultura, IPHAN, parceria IPOL/UFSC 2016-2018, QUADROS et al. 2018) e o desenvolvimento do Portal de Libras (LIBRAS, 2020) que inclui parcerias com vários pesquisadores brasileiros e internacionais para descrever a Libras (CNPQ Processo 440337/2017-8).

A primeira gramática da Libras resultante de nossas pesquisas apresenta uma versão em Libras que estará disponível no Portal de Libras (LIBRAS, 2020), com acesso público, na interface voltada para professores da rede pública e privada brasileira, portal que estará disponível no âmbito de um projeto que conta com financiamento do CNPQ (Processo 440337/2017-8). Para o desenvolvimento desta primeira gramática na versão em Libras, foram estabelecidos aspectos metodológicos que serão apresentados neste artigo.

\section{CORPUS DE LIBRAS}

\subsection{O QUE É CORPORA DE LÍNGUAS?}

Corpora de línguas são registros de diferentes gêneros textuais escritos e falados de diferentes línguas. Segundo O’Keeffe e Maccarthy (2010), a ideia de corpus de uma língua começou em 1960 com os estudos lexicográficos. Com o avanço da tecnologia, os corpora começaram a ser compilados com o uso de computadores. A exemplo disso, os autores citam o primeiro corpus do inglês que foi coletado e organizado na Brown University com um milhão de palavras do inglês de textos literários. A partir de 1970, já havia vários corpora de línguas sendo estabelecidos. Maccarthy e O’Keeffe mencionam que os corpora servem para disponibilizar dados linguísticos em quantidade para possibilitar a verificação de padrões que são usados. Assim sendo, a linguística de corpus viabiliza o acesso a grandes quantidades de dados para que os linguistas possam explicar os fenômenos linguísticos. A tarefa do linguista passa, então, a ser a elaboração de metodologias confiáveis para descrever e dar conta dessas evidências linguísticas a partir de dados disponibilizados em corpora de línguas diversas. Os autores ainda discutem a questão do tamanho do corpus. Há um movimento na linguística de corpus de megacorpus para minicorpus, no sentido de organização de um corpus específico para atender a determinados objetivos, conforme a proposta da pesquisa. Além disso, com a revolução da internet, cada vez mais temos acesso a diferentes corpora que vão de monomodal a multimodal, ou seja, os dados linguísticos incluem além da informação verbal ou escrita, informações corporais, imagéticas, sonoras e, em algumas circunstâncias, até táteis e olfativas.

Os autores definem corpus como compêndio linguístico de um texto (parole) com evidências para a compreensão sobre a língua (langue) com dois objetivos centrais: (1) verificar a extensão de um padrão encontrado (valor descritivo) e (2) analisar os fatores 
contextuais que influenciam a variabilidade (valor explicativo). Esses objetivos exigem a identificação e a análise de ocorrências no uso da língua e, para conclusões mais abrangentes sobre um fenômeno linguístico, é necessária uma grande quantidade de dados de diferentes usuários da língua. Esses são alguns dos problemas metodológicos levantados por Maccarthy e O’Keeffe (2010).

\subsection{O CORPUS DA LIBRAS}

Para a elaboração das gramáticas da Libras, usamos um corpus partindo do princípio de que este compreende um banco de produções de uma língua organizado por diferentes tipos e gêneros textuais sinalizados para fins de registro da língua. No caso específico do corpus em questão, o Corpus de Libras (2020), temos vários conjuntos de produções da Libras organizados a partir de projetos de pesquisa com diferentes propostas, mas todos têm em comum o registro de interações em Libras seguindo a metodologia do Inventário Nacional da Libras (ver Quadros, Silva, Machado e Ludwig, neste dossiê), por meio de filmagens em vídeo e transcrições usando o Sistema de Anotação Eudico - ELAN [https://tla.mpi.nl/tools/tla-tools/elan/] (QUADROS, 2016).

O material do Corpus de Libras já transcrito e traduzido está sendo usado como referência da descrição de aspectos linguísticos da primeira versão da Gramática da Libras, em Libras, apresentada neste artigo.

\section{GRAMÁTICAS DE LÍNGUAS DE SINAIS}

\subsection{GRAMÁTICAS DE LÍNGUAS DE SINAIS NA EUROPA: PROJETO SIGNGRAM BLUEPRINT}

O SignGram Blueprint (2020) é uma ferramenta desenvolvida no escopo de um projeto chamado SignGram COST Action (IS1006) que objetiva mapear as gramáticas das línguas de sinais europeias, considerando que este mapeamento permite a cidadania de sinalizantes surdos e a proteção de suas heranças linguísticas. COST é uma rede europeia com atividades de pesquisas nacionais que promovem e financiam projetos científicos com um objetivo específico. O SignGram COST Action foi um projeto conduzido no período de 2011 a 2015 para criar o Blueprint. Foi um projeto que reuniu 13 países europeus. O Blueprint é uma ferramenta de openaccess podendo ser acessada por quaisquer interessados para escrever gramáticas de línguas de sinais. O Blueprint compreende um manual e um checklist que orienta o processo de elaboração da gramática.

Após o desenvolvimento da ferramenta, os pesquisadores aprovaram um novo projeto de pesquisa, o SIGN-HUB (2016-2020) para disponibilizar online as seguintes gramáticas de línguas de sinais: Língua de Sinais Alemã, Língua de Sinais Italiana, Língua de Sinais Espanhola, Língua de Sinais Catalã, Língua de Sinais Holandesa e Língua de Sinais Turca (SIGN-HUB, 2020).

A Língua Brasileira de Sinais se integra a esta proposta, iniciando a descrição gramatical de alguns dos aspectos compreendidos no checklist do SignBram Blueprint. Os aspectos abordados iniciam com uma contextualização sociolinguística das práticas linguísticas que compreendem a Libras, a formação dos sinais, a formação das sentenças, a formação dos textos (aspectos relacionados à coesão e coerência, gêneros discursivos e produções criativas).

\subsection{GRAMÁTICA DA LIBRAS}

Há algumas publicações no Brasil que são referidas como estudos gramaticais da Libras (FERREIRA-BRITO, 1995; QUADROS; KARNOPP, 2004; Série de Estudos da Língua de Sinais, volumes 1, 2 e 3 ).

No entanto, tais publicações apresentam apenas alguns dos aspectos linguísticos específicos que serão abordados na gramática da Libras proposta nesta pesquisa. Segue um quadro síntese destas publicações: 


\begin{tabular}{l|l} 
Publicação & \multicolumn{1}{c}{ Síntese } \\
\hline Ferreira-Brito (1995) & $\begin{array}{l}\text { Neste livro, Ferreira-Brito apresenta a primeira descrição da Libras. A autora apresenta aspectos } \\
\text { gerais da fonologia, morfologia, semântica, pragmática e sintaxe. Os aspectos linguísticos } \\
\text { abordados compreendem a negação, os pronomes e os classificadores. No nível lexical, a autora } \\
\text { aborda empréstimos linguísticos em Libras. A autora também apresenta uma análise das } \\
\text { modalidades epistêmicas e deodônticas da Libras. A autora discute aspectos metodológicos da } \\
\text { pesquisa da Libras, incluindo uma primeira proposta de um sistema de transcrição de } \\
\text { enunciados e textos em línguas de sinais. No capítulo final, a autora apresenta uma comparação } \\
\text { inicial entre a Libras e a Língua de Sinais Kaapor Brasileira. A obra compreende o primeiro } \\
\text { registro de aspectos gramaticais realizado sobre a Libras no país. }\end{array}$
\end{tabular}

Quadros e Karnopp (2004)

Quadros e Karnopp (2004) iniciam a obra com uma discussão sobre o estatuto linguístico da Libras. A partir disso, introduzem uma análise de aspectos fonológicos, morfológicos e sintáticos. As análises resultam das teses das autoras que apresentam descrições detalhadas sobre os aspectos linguísticos abordados. No nível fonológico, as autoras apresentam uma análise dos fonemas que constituem a Libras e, também, de processos fonológicos que se aplicam à Libras. No nível morfológico, foram abordados, de maneira geral, aspectos quanto aos processos de formação dos sinais, considerando os processos derivacionais e os flexionais. No nível sintático, é apresentada uma análise detalhada das estruturas das frases da Libras, compreendendo uma descrição da composição da sentença e dos diferentes tipos de estruturas: negativas, interrogativas polar, interrogativas QU, condicionais, tópico e foco.

Quadros, Stumpf e Leite (2013) Série Estudos da Língua Brasileira de Sinais, volume 1

Stumpf, Quadros e Leite (2014) Série Estudos da Lingua Brasileira de Sinais, volume II
A Série Estudos da Língua Brasileira de Sinais compreende produções de pesquisa de vários autores brasileiros em duas áreas de investigação: (1) Linguística e Estudos da Tradução. Os diferentes estudos descritos compreendem temas específicos de dissertações e teses em diferentes programas brasileiros. Os fenômenos linguísticos compreendem aspectos específicos variados, tais como, a organização de morfemas livres e presos na Libras (NASCIMENTO, 2013); uma análise do sistema quantificacional na Libras (FINAU, 2014), indicadores de formalidades na Libras (Silva, 2011); simetria e ritmo na Libras (KLAMT, 2014); estrutura narrativa na Libras (NEVES, 2013). 
Quadros e Weininger (2014) Série Estudos da Lingua Brasileira de Sinais, volume III

Além destas publicações, há dissertações e teses sobre a Libras produzidas a partir da década de 90, com uma grande intensificação dos estudos depois da virada do milênio (QUADROS, 2013). Foi realizado um levantamento de teses e dissertações que estão contempladas na gramática da Libras em Libras (com publicação prevista para o segundo semestre 2020) por meio de um apêndice incluindo todos os resumos dos trabalhos concluídos do âmbito da linguística traduzidos para a Libras.

\section{METODOLOGIAS QUE NORTEIAM A ELABORAÇÃO DAS GRAMÁTICAS DA LIBRAS}

Uma metodologia para constituição de uma gramática de línguas de sinais parte de dados que constituem o corpus que serve de referência para a sua produção. As gramáticas da Libras que estamos desenvolvendo se constituem a partir de vários estudos com diferentes autores e corpora da Libras, mas sempre sendo corroborada por meio dos dados que constituem o Corpus da Libras do Inventário Nacional de Libras (ver descrição no artigo Inventário Nacional de Libras de Quadros, Silva, Machado e Ludwig, neste dossiê). Também estamos utilizando as referências de constituição de gramáticas de outras línguas de sinais, tais como a proposta metodológica do SignGram Blueprint que integra um projeto europeu de elaboração de gramáticas das línguas de sinais europeias.

\subsection{METODOLOGIA DO SIGNGRAM BLUEPRINT}

O SignGram Blueprint é uma ferramenta para ser usada pelo linguista que irá descrever uma língua de sinais. Segundo Quer e Cecchetto (2014), o SignGram Blueprint foi desenvolvido com uma lista exaustiva para inventariar de aspectos gramaticais a serem descritos. Os autores se inspiraram no questionário de estudos linguísticos descritivos de Comrie e Smith (1977), mas sofisticaram a ferramenta, incluindo informações adicionais ao documento para orientar o linguista na descrição das línguas, a exemplo de materiais para eliciar dados. A ferramenta consiste de dois componentes principais: (a) uma tabela de conteúdos e (b) um manual de instruções. A tabela de conteúdos apresenta uma lista para ser verificada pelo linguista, item a item, na língua a ser descrita. O manual é um guia com instruções e informações mais detalhadas sobre cada aspecto listado para verificação na gramática da língua. Quer e Cecchetto (2014) conceberam estes componentes no sentido de incluir uma descrição e definição de cada aspecto gramatical, apresentação de exemplos representativos da língua de sinais, testes que podem ser usados para identificar cada fenômeno linguístico descrito, materiais disponíveis sobre eliciação de dados linguísticos e referências bibliográficas.

O Blueprint está organizado a partir de níveis linguísticos principais (fonologia, morfologia, sintaxe e semântica), bem como no nível lexical. Esta ferramenta está disponível abertamente por meio de um documento eletrônico que inclui também exemplos em vídeo de diferentes línguas de sinais. Segue um exemplo destas listas. 


\section{Part3 Lexicon}

\section{Chapter 1. The native lexicon}

Core lexicon

Non-core lexicon

Classifier constructions

Pointing

Buoys

Interaction between core and non-core lexicon

Lexicalization processes

Modification of core lexicon signs

Simultaneous constructions and use of the non-dominant hand

Quadro 1: Exemplo da lista de itens a serem considerados no escopo lexical

Fonte: SignGram Blueprint (2020)

No guia do SignGram Blueprint, aparece o detalhamento e as orientações relativas a esta lista. O detalhamento apresenta uma introdução sobre o que significa realizar uma descrição gramatical e de como usar o Blueprint. Cada nível linguístico apresenta seções de introdução, informações gerais, definições, classificações e sugestões de como implementar a descrição com possíveis desafios com que o linguista pode se deparar. Após esta parte, há também materiais de eliciação do nível linguístico abordado. O guia aborda os níveis linguísticos de forma exaustiva, mas cabe ao pesquisador tomar as decisões do que incluir na gramática a ser descrita. O guia também inclui um glossário que orienta os linguistas quanto à terminologia empregada. Segue um trecho do manual referente à Parte 3 listada acima sobre o Léxico:

\section{Chapter 1. The native lexicon}

\section{Definitions and challenges}

What is the native lexicon?

The native lexicon includes all signs developed within that language. [...]

In order to study the native lexicon of a sign language, it is necessary to have a basic understanding of the language's phonology, and much of this work will be covered in the phonology part of the grammar. [...]

A series of properties characterize and differentiate the core and non-core lexicon, based on phonological, morphosyntactic, and semantic criteria. Johnston \& Schembri (1999) propose following list for Auslan:

Table Lexicon-1: Properties that characterize signs in the core and the non-core lexicon (adapted from Table 1 in Johnston \& Schembri

(1999:136)

\begin{tabular}{|c|c|}
\hline Core lexicon & Non-core lexicon \\
\hline $\begin{array}{c}\text { Phonologically restricted in parameters and structure (subject to } \\
\text { phonological constraints, e.g. the dominance condition) }\end{array}$ & $\begin{array}{l}\text { Makes use of a wider range of parameters and frequently violates } \\
\text { phonological constraints. }\end{array}$ \\
\hline $\begin{array}{c}\text { Space is exploited as the phonological parameters of location of } \\
\text { movement. }\end{array}$ & Space and movement are used topographically/isomorphically. \\
\hline Subunits are discrete and categorical; variation is allophonic. & $\begin{array}{l}\text { Forms exhibit gradience: variations in form create changes in } \\
\text { meaning. }\end{array}$ \\
\hline$[\ldots]$ & {$[\ldots]$} \\
\hline
\end{tabular}

Quadro 2: Exemplo do manual do SignGram Blueprint

Fonte: SignGram Blueprint (2020) 
A seguir, será apresentada a metodologia que usamos na constituição da Gramática da Libras, em Libras, que também compreenderá uma versão da Gramática da Libras no formato impresso (em elaboração).

\subsection{DESCRIÇÕES METODOLÓGICAS PARA A ELABORAÇÃO DAS GRAMÁTICAS DA LIBRAS}

A presente pesquisa está utilizando os dados do Corpus de Libras, especificamente do Inventário Nacional de Libras dos surdos como referência. Esse inventário foi constituído seguindo a proposta do Inventário Nacional da Diversidade Linguística (INDL) do Instituto do Patrimônio Histórico e Artístico Nacional (IPHAN, 2020), do Ministério da Cultura. Na proposta do INDL, há guias que apresentam uma metodologia para inventariar as línguas brasileiras. Nós utilizamos essa metodologia do INDL, que inclui as pessoas de referência de uma dada comunidade linguística - no nosso caso, os surdos de referência. Essas pessoas são consideradas referências por serem lideranças, por serem conhecedoras profundas das línguas e manifestações culturais, sociais e políticas das comunidades linguísticas a que pertencem. Assim, foram 35 surdos de referência que integraram o Inventário Nacional da Libras (QUADROS et al. 2018).

Os surdos de referência que integram o Inventário Nacional de Libras participaram de um Seminário e de uma formação sobre o INDL com o objetivo de serem agentes multilplicadores do registro da Libras no Brasil (Seminário 8 e 9 de maio de 2017). Além da formação, esses surdos participaram de filmagens, que compreenderam entrevistas sobre sua inserção na comunidade surda, narrativas e produção de vocabulário. Esse material está disponível na página do Corpus de Libras (QUADROS et al., 2020).

Os dados produzidos em Libras pelos surdos de referência foram transcritos compreendendo 1.093 horas e 11 minutos de produções em Libras, com 80.050 sinais transcritos produzidos com a mão direita e mais 49.478 sinais transcritos produzidos com a mão esquerda dos surdos de referência, 13.620 sinais transcritos de sinais produzidos com a mão direita e 6.036 sinais produzidos com a mão esquerda do interlocutor.

A partir desse material com base no uso da Libras e considerando também aspectos da metodologia do SignGram Blueprint, constitui-se a descrição gramatical dos seguintes aspectos da Libras:

Aspectos sócio-históricos (a comunidade de sinalizantes da Libras, o estatuto da Libras, o estudo linguístico, variação sociolinguística);

- $\quad$ Nível fonológico: estrutura sublexical (articuladores ativos, locação, movimento, marcadores não-manuais, prosódia, processos fonológicos);

Nível lexical: o léxico nativo e o léxico não nativo (classificadores, apontação, bóias, soletração, sinais iniciados com letras do alfabeto manual, articulação da boca, empréstimos); classes de palavras (nome, verbo, adjetivos, advérbios, pronomes, conjunções, numerais, quantificadores, partículas, interjeições);

Nível morfológico: composição, derivação, flexão verbal, flexão nominal, classificadores;

Nível sintático: tipos de sentença (declarativas, interrogativas, imperativas, exclamativas, negativas,); estrutura frasal (estrutura argumental e transitividade, tipos de predicados, predicação não-verbal, existenciais e possessivos, funções gramaticais sujeito e objeto - argumentos e adjuntos, ordem das palavras, argumentos nulos, cópia do pronome); parataxe, hipotaxe e encaixadas (marcações manuais e não-manuais, orações relativas, orações adverbiais, condicionais, orações temporais, orações locativas, orações de maneira, orações concessivas, orações adjetivas, orações abolitivas, orações comparativas);

Nível textual: coesão e coerência, estrutura da narrativa, gêneros textuais, usos criativos da Libras.

Estamos incluindo também uma seção específica para abordar o uso dos espaços na Libras, considerando o uso do espaço abstrato, uso do espaço topográfico, expressões temporais, perspectiva, para a versão impressa.

Também estão sendo consideradas as pesquisas já realizadas pelos pesquisadores brasileiros em diferentes universidades do país que resultaram em dissertações e teses com análises de aspectos gramaticais específicos, bem como publicações em periódicos de 
resultados de pesquisas. Até o presente foram coletados os seguintes trabalhos que contemplam os níveis linguísticos que serão incluídos na gramática da Libras proposta no escopo do projeto:

\begin{tabular}{|c|c|}
\hline Aspectos sócio-históricos & $\begin{array}{l}\text { (PERLIN, 1998; MIRANDA, 2001; STROBEL, 2008; DINIZ, 2010; } \\
\text { QUADROS E CAMPELLO, 2010; CAMPELLO, 2011; SCHMITT, } \\
\text { 2013; QUADROS, 2015; QUADROS, 2017a) }\end{array}$ \\
\hline Nível fonológico & (KARNOPP, 1994, 1999; XAVIER, 2006, 2014) \\
\hline Nível lexical & (NASCIMENTO, 2009; PIZZIO, 2011; OLIVEIRA, 2015) \\
\hline Nível morfológico & $\begin{array}{l}\text { (BERENZ, 1996; FINAU, 2004; FINAU E MAZZUCHETTI, 2015; } \\
\text { QUADROS, 2004; NASCIMENTO, 2009; SILVA, 2010; QUADROS; } \\
\text { QUER, 2010; DEDINO, 2012; FERREIRA, 2013; XAVIER; NEVES, } \\
\text { 2016; WANDERLEY, 2017) }\end{array}$ \\
\hline Nível sintático & $\begin{array}{l}\text { (QUADROS, 1995, 1999; FERREIRA-BRITO, 1995; FELIPE, } 1998 \text {, } \\
\text { 2006; ARROTÉIA, 2005; PIZZIO, 2006; NUNES; QUADROS, 2008; } \\
\text { LEITE, 2008; SILVA, 2013; MIRANDA, 2014; LOURENÇO, 2014; } \\
\text { ANDRADE, 2015; SABANAI, 2016; ROYER 2019). }\end{array}$ \\
\hline Espaço na língua de sinais & $\begin{array}{l}\text { (QUADROS, 1995; BERENZ, 1996; LEITE, 2008; CAMPELLO, 2008; } \\
\text { SILVA, 2011; LUCHI, 2013) }\end{array}$ \\
\hline
\end{tabular}

Fonte: a autoria

A tarefa está compreendendo a validação das pesquisas com os dados do Corpus de Libras e a análise documental de todas estas pesquisas em uma publicação para disponibilizar um material acessível devidamente organizado. Assim, a partir do conjunto dessas pesquisas já realizadas, a análise dos dados do Corpus de Libras e o levantamento com base no SignGram Blueprint será, então, concluída uma gramática geral da Libras, abrangendo os aspectos linguísticos já mencionados para ser disponibilizada à comunidade.

A proposta foi de compor uma primeira versão da gramática da Libras em Libras que será apresentada na próxima seção. Posteriormente, haverá também uma gramática na versão impressa com todos os exemplos da Libras disponíveis online no Portal de Libras (libras.ufsc.br). Ambas versões compreendem a colaboração de vários pesquisadores do Brasil: Aline Lemos Pizzio, Aline Nunes de Sousa, Ana Regina e Souza Campello, Anderson Almeida da Silva, André Xavier, Angélica Rodrigues, Bruna Crescêncio Neves, Bruno Gonçalves Carneiro, Carlos Roberto Ludwig,, Carolina Pego, Charley Soares, Débora Campos Wanderley, Felipe Aleixo, Fernanda de Araújo Machado, Guilherme Lourenço, Jair Barbosa da Silva, João Paulo Ampessan, José Ishac Brandão El Khouri, Liona Paulus, Marcos Luchi, Marianne Rossi Stumpf, Marilyn Mafra Klamt, Miriam Royer, Rachel Sutton-Spence, Rimar Segala, Rodrigo Custódio da Silva, Rodrigo Nogueira Machado, Ronice Müller de Quadros e Sandra Patrícia Farias do Nascimento. 


\section{A PRIMEIRA GRAMÁTICA DA LIBRAS EM LIBRAS}

A primeira versão da gramática da Libras foi produzida totalmente em Libras e estará disponível no Portal de Libras (2020) [http://libras.ufsc.br]. A produção desta gramática foi feita de forma colaborativa com vários pesquisadores. A seguir, relatamos o processo de elaboração desta gramática.

A Gramática da Libras em Libras foi elaborada a partir de várias pesquisas produzidas incluindo dados do Inventário Nacional da Libras, dos surdos de referência. A proposta foi constituída por meio de roteiros que serviram de referência para a produção do conteúdo em Libras. O roteiro apresentou a seguinte estrutura:

1. Apresentação da Gramática da Libras

1.1. Objetivos desta gramática da Libras

1.2. O que é uma gramática?

1.3. Tipos de gramáticas

1.4. Tipo de gramática que estamos apresentando aqui

1.5. O Corpus de Libras - Surdos de Referência

1.6. Os dados da Libras apresentados na gramática com base nos usos

1.7. Os estudos gramaticais da Libras: os autores

1.8. Organização desta gramática

2. Libras e seus sinalizantes

2.1. A Libras e as comunidades surdas

2.2. Cultura surda

2.3. Educação de surdos

2.4. História da Libras

2.5. Legislação e Políticas Linguísticas

2.6. As pesquisas com língua de sinais

3. Sinais

3.1. A Fonética e a Fonologia das Línguas de Sinais

3.1.1. O que é fonética?

3.1.2. Fonemas

3.1.3. Fonética Articulatória Visual

3.1.4. Transcrição

3.1.5. Fonologia

3.2. Morfologia da Libras

3.2.1. Flexão e Derivação

3.2.2. Parte 1 Morfologia Simultânea própria flexão

3.2.3. Parte 2 Número-pessoal

3.2.4. Normal ou Puro

3.2.5. Reversa

3.2.6. Orientação da Mão

3.2.7. Flexão Aspectual

3.2.8. Flexão de número

3.2.9. Genero

3.2.10. Espaciais (afixos locativos)

3.2.11. Morfologia Sequência própria Derivação

3.2.12. Composição

3.2.13. Incorporação 
3.2.14. Aglomeração

3.2.15. Morfema-boca

3.3. Classificadores (descritivos imagéticos)

3.4. Empréstimos linguísticos na Libras

3.4.1. Empréstimos Linguísticos de Línguas Orais para Libras

3.4.2. Empréstimos Linguísticos de Outras Línguas de Sinais para Libras

3.4.3. Reflexão sobre a importância do Empréstimo Linguístico na Libras

3.5. Terminologia em Libras

3.5.1. Desenvolvimentos de dicionários de libras em comuns

3.5.2. Desenvolvimento da língua de sinais de Moçambique (MARTINS; FERREIRA; MINEIRO, 2012)

3.5.3. Processos variacionais e derivacionais dos sinais

3.5.4. Neologismo

3.6. Variação lexical na Libras

4. Sentenças

4.1. Introdução

4.2. Ordem das sentenças na Libras

4.3. Outras possíveis ordenações de dados a partir de Quadros (1999), Arrotéia (2005), Royer (2019) e dados com base no Corpus de Libras para esta gramática

4.4. Articulação de orações

4.5. Tipos de parataxe/coordenação

4.6. Hipotaxe

4.6.1. Causais

4.6.2. Comparativas

4.6.3. Condicionais

4.6.4. Finais (ou de finalidade)

4.6.5. Temporais

4.7. Encaixadas (orações subordinadas)

5. Texto

5.1. O estudo do texto em língua de sinais

5.2. A coesão do texto sinalizado

5.2.1. O que é coesão?

5.2.2. Que funções tem coesão do texto?

5.2.3. Os procedimentos e recursos da coesão

5.2.4. Coesão textual: conceito e mecanismos

5.3. A coerência do texto sinalizado

5.3.1. O que é coerência?

5.3.2. Que funções tem a coerência do texto?

5.4. Níveis de (in)formalidade em Libras

5.5. Estrutura da Narrativa

5.6. Literatura em Libras

5.7. Gêneros textuais acadêmicos em Libras

5.7.1. Resumo

5.7.2. Resenha

5.7.3. Prova

5.7.4. Considerações finais sobre os gêneros textuais acadêmicos em Libras 
Esta é a estrutura da Gramática da Libras em Libras que inclui também um glossário com o termos usados na gramática, além de resumos de teses e dissertações sobre estudos linguísticos da Libras a partir de um levantamento realizado no Portal da Capes e resumos de dez artigos de referência sobre estudos linguísticos de línguas de sinais produzidos por pesquisadores internacionais. Todo o material está sendo disponibilizado em Libras com tradução para a Língua Portuguesa produzida por meio de dublagem, com acesso público.

A próxima etapa desta gramática será disponibilizada na forma impressa com acesso a todos os exemplos coletados do Corpus de Libras em Libras, compreendendo novos estudos sobre a gramática da Libras, incluindo novos autores.

\section{REFLEXÕES SOBRE A CONSTITUIÇÃO DE GRAMÁTICAS DA LIBRAS}

Após ter concluído a produção da primeira gramática de Libras em Libras, concluímos que as gramáticas da Libras precisam ser em Libras ou serem híbridas, contendo textos em português com produções em Libras. Falar sobre a Libras em Libras traz uma nova perspectiva sobre os estudos linguísticos da Libras, pois tivemos a oportunidade de experimentar a própria Libras para falar sobre a Libras. Usar a língua na sua função metalinguística propicia novas formas discursivas que impõem uma elaboração linguística diferenciada e, ao mesmo tempo, exigem formas reflexivas de empacotar as informações em forma textual de modo apropriada a apresentar a própria língua. Este exercício ao qual nos desafiamos foi muito importante para os estudos da Libras, assim como para os estudos linguísticos de forma geral. Ademais, produzir e propagar conhecimentos em uma dada língua é valorizá-la, bem como um compromisso ético com seus usuários. Como pesquisadores de Libras, nós, os autores da Gramática da Libras em Libras, sentimo-nos intimados a dar esse retorno à comunidade surda brasileira.

Ainda precisamos reiterar as questões éticas que permeiam a elaboração das gramáticas da Libras. Essas gramáticas precisam ser constituídas por autores surdos, mesmo que em parceria com autores ouvintes, afinal de contas, a Libras é uma língua de sinais estabelecida nas comunidades surdas brasileiras. Nós sabemos que as línguas são de quem as usa, isso significa que as línguas são de surdos e ouvintes. No entanto, a razão das línguas de sinais continuarem existindo no mundo se dá porque os surdos se encontram e usam uma língua de sinais, mesmo que já tenham sido proibidos por outros ouvintes de usá-la em diferentes momentos da História. Essas línguas de sinais formam um dos pilares da constituição identitária das comunidades surdas aqui no Brasil e em qualquer parte do mundo. Os ouvintes se encontram e usam uma língua falada. Os surdos, por outro lado, se encontram e usam uma língua de sinais. As línguas de sinais, assim como a Libras, são línguas que se constituem a partir do olhar e do corpo. É uma tradução da natureza humana de comunicação em uma forma visual, espacial e corporal. Assim, as formas de pensar, de criar, de produzir conhecimento são manifestadas pelo corpo por meio das mãos, da face, da composição dos olhares, dos movimentos e dos espaços em forma de língua. Essas manifestações linguísticas traduzem também as formas de ser dos surdos. Aí é que os surdos tornam-se protagonistas importantes. Da mesma forma que todas as línguas no mundo são estudadas por linguistas quase que na íntegra nativos da língua, precisamos garantir que os surdos sejam autores das gramáticas da Libras. Claro que também sabemos que temos linguistas que estudam outras línguas que não são suas línguas nativas, mas isso não é a regra. Da mesma forma, afirmamos aqui que não deve ser a regra dos estudos da Libras. Quando linguistas estudam outras línguas, normalmente eles estabelecem parcerias com outros linguistas nativos da língua a ser estudada. Os pesquisadores ouvintes, portanto, precisam estabelecer parcerias com os pesquisadores surdos na constituição das gramáticas da Libras.

Dessa forma, a Gramática da Libras contou com pesquisadores surdos e ouvintes que trabalharam juntos para torná-la possível e essa parceria deve ser assegurada como parte constitutiva de outras gramáticas que podem e devem ser elaboradas com o propósito de descrever a Libras, língua ainda carente de descrições gramaticais em todos os níveis de análise, do fonético ao discursivo.

\section{AGRADECIMENTOS}

Este trabalho foi possível pelos recursos do Conselho Nacional de Desenvolvimento Científico e Tecnológico - CNPQ (\# 440337/2017-8, \#304179/2017-5). Como forma de reconhecimento a todos os Surdos que participaram/participam dos diversos 
projetos que temos desenvolvido nas Universidades Brasileiras, faremos um agradecimento nominal aos Surdos que participaram da elaboração da Gramática da Libras em Libras, o qual é extensivo a todos os Surdos brasileiros: Ana Regina e Souza Campello (UFRJ); Charley Soares (UFV); Débora Campos Wanderley (UFSC); Fernanda de Araújo Machado (UFSC); João Paulo Ampessan (UFSC); José Ishac Brandão El Khouri (UFT); Liona Paulus (UzK); Marianne Rossi Stumpf (UFSC); Miriam Royer (UFSC); Rimar Segala (UFSCar); Rodrigo Custódio da Silva (UFSC); Rodrigo Nogueira Machado (UFC).

\section{REFERÊNCIAS}

ANDRADE, A. de M. F. Causatividade em Libras. 2015. Dissertação (Mestrado em Linguística) - Programa de Pós-Graduação em Linguística. Universidade de Brasília, Brasília, Distrito Federal, 2015.

ARROTÉIA, J. O papel da marcação não-manual em sentenças negativas na Língua de Sinais Brasileira. 2005. Dissertação (Mestrado) - Instituto de Estudos da Linguagem, Universidade de Campinas, Campinas, São Paulo, 2005.

BERENZ, N. F. Person and deixis in Brazilian Sign Language. 1996. Dissertation (Ph.D in Linguistics) - Department of Linguistics, University of California, Berkeley, 1996.

BRASIL. Lei Federal n. 10.436, de 24 de abril de 2002. Presidência da República Casa Civil. Dispõe sobre a Língua Brasileira de Sinais - Libras e dá outras providências. Brasília, Distrito Federal, N. 181ํ da Independência e 114o da República, p. 1, 25 abr. 2002. Disponível em: http://www.planalto.gov.br/ccivil_03/leis/2002/L10436.htm. Acesso em: 10 jan. 2020.

CAMPELlO, A. R. e S. Aspectos da visualidade na educação de surdos. 2008. Tese (Doutorado em Educação) - Programa de PósGraduação em Educação, Universidade Federal de Santa Catarina, Florianópolis, 2008.

CAMPELlO, A. R e S. A Constituição Histórica da Língua de Sinais Brasileira: Século XVIII a XXI. Revista Mundo \& Letras, José Bonifácio, São Paulo, v.2, p. 8-25, 2011.

CHACON, T. C. et al. Guia de pesquisa e documentação para o INDL: patrimônio cultural e diversidade linguística e pesquisa. Iphan, Brasília, Distrito Federal, $\quad$ v. $\quad 1, \quad 95 \quad$ p.. $\quad 2014 . \quad$ Disponível em: http://portal.iphan.gov.br/uploads/ckfinder/arquivos/Guia\%20de\%20Pesquisa\%20e\%20Documenta\%C3\%A7\%C3\%A3o\%20para \%200\%20INDL\%20-\%20Volume\%201.pdf. Acesso em: 26 maio 2020.

CHACON, T. C. et al. Guia de pesquisa e documentação para o INDL: patrimônio cultural e diversidade linguística e pesquisa. Iphan, Brasília, Distrito Federal, v. 2, $103 \quad$ p., $2014 . \quad$ Disponível em: http://portal.iphan.gov.br/uploads/ckfinder/arquivos/Guia\%20de\%20Pesquisa\%20e\%20Documenta\%C3\%A7\%C3\%A3o\%20para \%20o\%20INDL\%20-\%20Volume\%202.pdf. Acesso em: 26 maio 2020.

CHOMSKY, N. Knowledge of language: its origin, nature and use. New York: Praeger, 1986.

COMRIE, B. e SMITH, N. Língua Descriptive Studies Questionnaire. [1977]. Instituto Max Planck de Antropologia Evolucionária, Departamento de Linguística. Disponível em: http://www.eva.mpg.de/lingua/tools-at-lingboard/questionnaire/linguaQ.php. Acesso em: 25 jan. 2020.

DEDINO, M. de L. S. M. Incorporação de numeral na Libras. In: ALBRES, N. de A.; XAVIER, A. N. (org.). Libras em estudo: descrição e análise. São Paulo: Feneis, 2012.p. 123-139. 
DINIZ, H. G. A história da Libras: um estudo descritivo de mudanças fonológicas e lexicais. 2010. Dissertação (Mestrado em Linguística) - Programa de Pós-Graduação em Linguística, Universidade Federal de Santa Catarina, Florianópolis, Santa Catarina, 2010 .

ELAN. Sistema Eudico Annotator. Disponível em: https://archive.mpi.nl/tla/elan. Acesso em: 16 abr. 2020.

FELIPE, T. A. de S. A relação sintático-semântica dos verbos e seus argumentos na LIBRAS. 1998. Tese (Doutorado em Linguística) Faculdade de Letras, Universidade Federal do Rio de Janeiro, Rio de Janeiro, 1998.

FELIPE, T. A. de S. Os processos de formação de palavra na Libras. Educação Temática Digital, Campinas, São Paulo, v. 7, n. 2, p. 200-217, jun. 2006.

FERREIRA-BRITO, L. Por uma gramática de língua de sinais. Rio de Janeiro: Tempo Brasileiro, 1995.

FERREIRA, G. A. Um estudo sobre os verbos manuais da Língua de Sinais Brasileira. 2013. Dissertação (Mestrado em linguística) Programa de Pós-Graduação em Linguística, Universidade de Brasília, Distrito Federal, 2013.

FINAU, R. A. Os sinais de tempo e aspecto na Libras. 2004. Tese (Doutorado em Letras) - Curso de Pós-Graduação em Letras, na Área de Estudos Linguísticos, Universidade Federal do Paraná, Curitiba, Paraná, 2004.

FINAU, R. A. Uma análise do sistema quantificacional da Libras. In: QUADROS, R. M. de; STUMPF, M. R. e LEITE, T. de A. (org.). Série Estudos da Língua Brasileira de Sinais. Florianópolis: Editora Insular, v. 2, 2014. p. 119-143.

FINAU, R. A.; MAZZUCHETTI, V. A Incorporação de numeral em estruturas classificadoras de Língua Brasileira de Sinais. Revista Virtual de Estudos da Linguagem. v. 13, n. 24, p. 67-86, 2015.

IPHAN. Instituto do Patrimônio Histórico e Artístico Nacional. Ministério da Cultura. 2020. Disponível em: http://portal.iphan.gov.br/Acesso em: 25 abr. 2020.

JOHNSTON, T.; SCHEMBRI, A. On defining lexeme in a signed language. Sign Language e Linguistics. v. 2, n.2, p. 115-185, 1999.

KARNOPP, L. B. Aquisição do Parâmetro Configuração de Mão dos Sinais da LIBRAS: estudo sobre quatro crianças surdas filhas de pais surdos. 1994. Dissertação (Mestrado) - Instituto de Letras e Artes, Pontifícia Universidade Católica do Rio Grande do Sul, Porto Alegre, Rio Grande do Sul, 1994.

KARNOPP, L. B. Aquisição fonológica na Língua Brasileira de Sinais: estudo longitudinal de uma criança surda. 1999. Tese (Doutorado em Letras) - Curso de Pós-Graduação em Letras, Faculdade de Letras, Pontifícia Universidade Católica do Rio Grande do Sul, Porto Alegre, Rio Grande do Sul, 1999.

KLAMT, M. M. O ritmo na poesia em língua de sinais. 2014. Dissertação (Mestrado em Linguística) - Programa de Pós-Graduação em Linguística, Universidade Federal de Santa Catarina, Florianópolis, Santa Catarina, 2014.

LEITE, T. de A. A segmentação da língua de sinais brasileira (libras): um estudo linguístico descritivo a partir da conversação espontânea entre surdos. 2008. Tese (Doutorado em Letras) - Programa de Pós-Graduação em Estudos Linguísticos e Literários em Inglês, Universidade de São Paulo, São Paulo, 2008.

LIBRAS. Portal de Libras. Disponível em: https://portal.libras.ufsc.br. Acesso em: 25 jan. 2021.

LIBRAS. Portal de Libras. Disponível em: https://libras.ufsc.br/. Acesso em: 25 abr. 2020. 
LOURENÇO, G. Concordância, caso e ergatividade em Língua de Sinais Brasileira: uma proposta minimalista. 2014. Dissertação (Mestrado em Linguística Teórica) - Faculdade de Letras, Universidade Federal de Minas Gerais, Belo Horizonte, Minas Gerais, 2014.

LUCHI, M. Interpretação de descrições imagéticas: onde está o léxico? 2013. Dissertação (Mestrado em Estudos da Tradução) Programa de Pós-Graduação em Estudos da Tradução, Universidade Federal de Santa Catarina, Florianópolis, Santa Catarina, 2013.

MIRANDA, J. P. V. Voz passiva em Libras? ou outras estratégias de topicalização? 2014. Dissertação (Mestrado em Linguística) Programa de Pós-Graduação em Linguística, Universidade de Brasília, Brasília, Distrito Federal, 2014.

MIRANDA, W. de O. Comunidade dos surdos: olhares sobre os contatos culturais. 2001. Dissertação (Mestrado em Educação) Programa de Pós-Graduação em Educação, Faculdade de Educação, Universidade Federal do Rio Grande do Sul, 2001.

NASCIMENTO, S. P. F. do. Representações lexicais da língua de sinais brasileira: uma proposta lexicográfica. 2009. Tese (Doutorado em Linguística) - Programa de Pós-Graduação em Linguística, Universidade de Brasília, Brasília, Distrito Federal, 2009.

NASCIMENTO, S. P. F. do. A organização dos morfemas livres e presos em LSB: reflexões preliminares. In: QUADROS, R. M. de; STUMPF, M. R;e LEITE, T. de A. (org.). Série Estudos da Língua Brasileira de Sinais, Florianópolis: Editora Insular, v. 1, 2013. p.79118.

NEVES, B. C. Competência narrativa: uma análise das produções das crianças bilíngues bimodais. 2013. Dissertação (Mestrado em Linguística) - Programa de Pós-Graduação em Linguística, Universidade Federal de Santa Catarina, Florianópolis, Santa Catarina, 2013.

NUNES, J.; QUADROS, R. M. de. Phonetic realization of multiple copies in Brazilian Sign Language. In: Theoretical Issues of Sign Language Research 8, 2008, Barcelona: Signs of the time. Selected papers from TISLR. Hamburg/Germany: Signum Press, v. 1, 2008. p. 179-192.

OLIVEIRA, J. S. de. Análise descritiva da estrutura querológica de unidades terminológicas do glossário letras-libras. 2015. Tese (Doutorado em Estudos da Tradução) - Programa de Pós-Graduação em Estudos da Tradução, Universidade Federal de Santa Catarina, Florianópolis, Santa Catarina, 2015.

O’KEEFFE, A.; MCCARTHT, M. (ed.). The Routledge Handbook of Corpus Linguistics. London, New York: Routledge, 2010.

PERLIN, G. Identidades surdas. In: SKLIAR, C. (org.). A surdez: um olhar sobre as diferenças. Porto Alegre: Mediação, 1998. p. 5273.

PIZZIO, A. L. A variabilidade da ordem das palavras na aquisição da língua de sinais brasileira: construções com tópico e foco. 2006. Dissertação (Mestrado em Linguística) - Programa de Pós-Graduação em Linguística, Universidade Federal de Santa Catarina, Florianópolis, Santa Catarina, 2006.

PIZZIO, A. L. A tipologia linguística e a língua de sinais brasileira: elementos que distinguem nomes de verbos. 2011. Tese (Doutorado em Linguística) - Programa de Pós-Graduação em Linguística, Universidade Federal de Santa Catarina, Florianópolis, Santa Catarina, 2011.

QUADROS, R. M. de. As categorias vazias pronominais: uma análise alternativa com base na língua de sinais brasileira e reflexos no processo de aquisição. 1995. Dissertação (Mestrado) - Instituto de Letras e Artes, Pontifícia Universidade Católica do Rio Grande do Sul, Porto Alegre, Rio Grande do Sul, 1995. 
QUADROS, R. M. de. Phrase structure of Brazilian Sign Language. Tese (Doutorado em Linguística Aplicada) - Faculdade de Letras, Curso de Pós-Graduação em Letras, Pontifícia Universidade Católica do Rio Grande do Sul, Porto Alegre, Rio Grande do Sul, 1999.

QUADROS, R. M. de. Gramática da língua de sinais brasileira: os diferentes tipos de verbos e suas repercussões na sintaxe. Revista da ANPOLL, São Paulo, v. 1, n. 16, p. 289-320, 2004.

QUADROS, R. M. de. Contextualização dos estudos linguísticos sobre a Libras no Brasil. In: QUADROS, R. M. de; STUMPF, M. R.; LEITE, T. de A. (org.). Série Estudos da Língua Brasileira de Sinais. Florianópolis: Editora Insular, v. 1, 2013, p.15-36.

QUADROS, R. M. de. Letras Libras: ontem, hoje e amanhã. Florianópolis: Editora da UFSC, 2015.

QUADROS, R. M. de. A transcrição de textos do Corpus de Libras. Revista Leitura, Maceió, n.57, v 1, n.57, p.8-34, jan./jun. 2016.

QUADROS, R. M. de. Língua de herança: língua brasileira de sinais. Porto Alegre: Editora Penso, 2017.

QUADROS, R. M. de, CAMPELLO, A. R. e S. Constituição política, social e cultural da Língua Brasileira de Sinais. In: VIEIRAMACHADO, L. M.; LOPES, M. C. (org.). Educação de surdos: políticas, língua de sinais, comunidade e cultura surda. Santa Cruz, Rio Grande do Sul: EDUNISC, v.1, 2010. p. 15-47.

QUADROS, R. M. de; KARNOPP, L. B. Lingua de sinais brasileira: estudos linguísticos. Porto Alegre: Artmed, 2004.

QUADROS, R. M. de; PIZZIO, A. L. Aspectos fonético-fonológicos da Libras. Teresina: Fuespi, 2015.

QUADROS, R. M. de; QUER, J. A caracterização da concordância nas línguas de sinais.. In: Heloisa Maria Moreira Lima-Salles, Rozana Reigota Naves. (org.). Estudos Gerativos da língua de sinais brasileira e de aquisição do português (L2) por surdos. Goiânia: Cânone Editorial, v. 1, 2010. p. 33-58.

QUADROS, R. M. de et al. Corpus de Libras. 2020. Disponível em: http://corpuslibras.ufsc.br/. Acesso em: 17 fev. 2020.

QUADROS, R. M.; NEVES, B. C.; LOHN, J. T.; SCHMITT, D. e LUCHI, Ml. Língua brasileira de sinais: patrimônio linguístico brasileiros Florianópolis: Editora Garapuvu, 2018.

QUADROS, R. M. de; STUMPF, M. R. e LEITE, T. de A. (org.). Série Estudos da Língua Brasileira de Sinais. Florianópolis: Editora Insular, v. 1, 2013.

QUADROS, R. M. de; STUMPF, M. R. e LEITE, T. de A. (org.). Série Estudos da Língua Brasileira de Sinais. Florianópolis: Editora Insular, v. 2, 2014.

QUADROS, R. M. de; WEININGER, M. J. (org.). Série Estudos da Língua Brasileira de Sinais. Florianópolis: Editora Insular, v. 3 , 2014.

QUER, J.; CECCETTO, C. A tool for sign language grammaticography: The SigBram Blueprint. In: BELKADI, A.; CHATSIOU, K.; ROWAN, K. (org.). Proceedings of Conference on Language Documentation and Linguistic Theory 4, London: School of Oriental and African Studies, University of London, 2014. Disponível em: www.hrelp.org/eprints/ldlt4_11.pdf. Acesso em: 25 jun. 2020.

ROYER, M. Análise da ordem das palavras nas sentenças em Libras do Corpus da Grande Florianópolis. 2019. Dissertação (Mestrado em Linguística) - Programa de Pós-Graduação em Linguística, Universidade Federal de Santa Catarina, Florianópolis, Santa Catarina, 2019. 
SABANAI, L. N. Aspectos gramaticais e discursivos da narrativa na Libras. 2016. Tese (Doutorado em Linguística) - Programa de Pós-Graduação em Linguística, Universidade de Brasília, Brasília, Distrito Federal, 2016.

SCHMITT, D. A história da língua de sinais em Santa Catarina: contextos sócio-históricos e sociolinguísticos de surdos de 1946 a 2010. 2013. Tese (Doutorado em Linguística) - Programa de Pós-Graduação em Linguística, Universidade Federal de Santa Catarina, Florianópolis, Santa Catarina, 2013.

SIGNGRAM BLUEPRINT. 2020. Disponível em: http://signgram.eu. Acesso em: 20 nov. 2020.

SIGN-HUB. 2020. Disponível em: https://www.sign-hub.eu. Acesso em: 20 nov. 2020.

SILVA, A. A. da. Sintagmas nominais: marcas de referencialidade e determinação na Libras. 2013. Dissertação (Mestrado em Letras) - Programa de Pós-Graduação em Letras, Universidade Federal do Piauí, Teresina, Piauí, 2013.

SILVA, L. Investigando a categoria aspectual na aquisição da língua brasileira de sinais. 2010. Dissertação (Mestrado em Linguística) - Programa de Pós-Graduação em Linguística, Universidade Federal de Santa Catarina, Florianópolis, Santa Catarina, 2010.

SILVA, R. C. Indicadores de formalidade no gênero monológico em libras. 2011. Dissertação (Mestrado em Linguística) - Programa de Pós-Graduação em Linguística, Universidade Federal de Santa Catarina, Florianópolis, Santa Catarina, 2011.

STROBEL, K. L. As imagens do outro sobre a cultura surda. Florianópolis: Ed. Da UFSC. 2008.

WANDERLEY, D. C. A classificação dos verbos com concordância da língua brasileira de sinais: uma análise a partir do SignWriting. 2017. Tese (Doutorado em Linguística) - Programa de Pós-Graduação em Linguística, Universidade Federal de Santa Catarina, Florianópolis, Santa Catarina, 2017.

XAVIER, A. N. Descrição fonético-fonológica dos sinais da língua de sinais brasileira (Libras). 2006. Dissertação (Mestrado em Linguística) - Pós-Graduação em Semiótica e Linguística Geral, Universidade de São Paulo, São Paulo, 2006.

XAVIER, A. N. Uma ou duas? Eis a questão! Um estudo do parâmetro número de mãos na produção de sinais da língua brasileira de sinais (libras). 2014. Tese (Doutorado em Linguística) - Instituto de Estudos da Linguagem, Universidade Estadual de Campinas, Campinas, São Paulo, 2014.

XAVIER, A. N.; NEVES, S. L. G. Descrição de aspectos morfológicos da Libras. Revista Sinalizar, Goiânia, v. 1, n. 2, p. 130-151, jul./dez. 2016.

\section{()(1) $\circledast$}

Recebido em 27/09/2020. Aceito em 29/10/2020. 